\title{
Ventilation Perfusion Scanning
}

National Cancer Institute

\section{Source}

National Cancer Institute. Ventilation Perfusion Scanning. NCI Thesaurus. Code C38100.

A nuclear imaging test that uses radiopharmaceuticals to produce an image of the blood flow to the lungs, that measures the ability of the lungs to inhale gas, and that assesses the gas distribution within the lungs. 